\title{
Pneumonectomy subjects with acute respiratory distress syndrome: what to do
}

To the Editor:

I read with interest the article on prone ventilation in acute respiratory distress syndrome (ARDS) by GuÉRIN [1] in the European Respiratory Review. In this extensive review, the author elaborated on the rationale, evidence and limitations of the application of prone position in ARDS patients. It is understood that excellent research has been conducted on the topic of prone position ventilation in ARDS. These findings have led to the authorisation of evidence-based medicine in prone ventilation in severe ARDS. In general, every intensive care clinician has to keep abreast of current developments in ARDS pathophysiology and management. The article by GUÉRIN [1] helps the clinician to comprehensively understand the benefits, limitations and complications of prone ventilation. This is necessary to acquire strong skills in the technique, which are highly nuanced.

There can be situations where rescue methods such as prone ventilation need to be used in patients with pneumonectomy. I wish to draw attention to two studies in which prone position was utilised for postpneumonectomy status subjects. The incidence of ARDS in post-lung resection subjects is reported to be 2.45 [2].

In a study from India by TATINENI et al. [3], a 57-year-old female patient with right-sided pneumonectomy presented to hospital with left lung pneumonia. She developed ARDS and was initially ventilated using lung protective ventilation. When this was unsuccessful, she was placed in the prone position and ventilated. The arterial oxygen tension/inspiratory oxygen fraction ratio before prone ventilation was $<100$ (i.e. 59). The duration of ventilation was $18 \mathrm{~h}$; the used tidal volume was $6 \mathrm{~mL} \cdot \mathrm{kg}^{-1}$ of ideal body weight, retaining lung protective strategies. This strategy proved successful and the patient was eventually discharged from the intensive care unit.

In Spain, CoRenjo et al. [4] used prone positioning for a 53-year-old male patient with severe respiratory failure post-left pneumonectomy surgery. The arterial oxygen tension/inspiratory oxygen fraction ratio before prone ventilation was $<100$ (i.e. 80 and 21 at the lowest point). The prone position was successfully utilised for $36 \mathrm{~h}$ with improvement in respiratory variables and no haemodynamic instability. The patient was successfully discharged from the intensive care unit. The authors concluded that extended prone ventilation can be considered in patients with severe respiratory failure post-pneumonectomy.

Based on these two studies it may be concluded that prone ventilation can be effectively utilised in patients with pneumonectomy irrespective of the lung that is resected. The improvements in physiological parameters may be the same but need to be understood with more clarity.

@ERSpublications

Successful management of ARDS with prone ventilation is challenging but possible in patients with pneumonectomy http://ow.ly/DgEiN

Ramesh Unnikrishnan

Dept of Respiratory Therapy, Manipal University, Manipal, Karnataka, India.

Correspondence: Ramesh Unnikrishnan, Dept of Respiratory Therapy, SOAHS, Manipal University, Manipal 576104, Karnataka, India. E-mail: rameshkris19@gmail.com

Received: Sept 012014 | Accepted: Sept 152014

Conflict of interest: None declared.

Provenance: Submitted article, peer reviewed.

References

1 Guérin C. Prone ventilation in acute respiratory distress syndrome. Eur Respir Rev 2014; 23: 249-257.

2 Dulu A, Pastores SM, Park B, et al. Prevalence and mortality of acute lung injury and ARDS after lung resection. Chest 2006; 130: 73-78.

3 Tatineni S, Sasikumar S, Shanbhag V. Prone position for management of refractory hypoxeamia in a patient with single lung. Ind J Respir Care 2012; 1: 69-72.

4 Cornejo R, Romero C, Goñi D. Prolonged prone position ventilation for severe respiratory distress syndrome post-pneumonectomy. Report of one case. Rev Med Chil 2009; 137: 1351-1356. 